\title{
Pathway analysis of systemic transcriptome responses to injected polystyrene particles in zebrafish larvae
}

\author{
Wouter J. Veneman $^{\mathrm{a}, \mathrm{b}}$, Herman P. Spaink ${ }^{\mathrm{b}}$, Nadja R. Brun ${ }^{\mathrm{a}}$, Thijs Bosker ${ }^{\mathrm{a}, \mathrm{c}}$, Martina G. Vijver ${ }^{\mathrm{a}, *}$ \\ a Institute of Environmental Sciences, Leiden University, P.O. Box 9518, 2300 RA Leiden, The Netherlands \\ b Institute of Biology, Leiden University, P.O. Box 9502, 2300 RA Leiden, The Netherlands \\ ${ }^{\mathrm{c}}$ Leiden University College, Leiden University, P.O. Box 13228, 2501 EE, The Hague, The Netherlands
}

\section{A R T I C L E I N F O}

\section{Keywords:}

Microplastic

Zebrafish embryo

RNA sequencing

Key event

Adverse outcome pathway

\begin{abstract}
A B S T R A C T
Microplastics are a contaminant of emergent concern in the environment, however, to date there is a limited understanding on their movement within organisms and the response of organisms. In the current study zebrafish embryos at different development stages were exposed to $700 \mathrm{~nm}$ fluorescent polystyrene (PS) particles and the response pathway after exposure was investigated using imaging and transcriptomics. Our results show limited spreading of particles within the larvae after injection during the blastula stage. This is in contrast to injection of PS particles in the yolk of 2-day old embryos, which resulted in redistribution of the PS particles throughout the bloodstream, and accumulation in the heart region. Although injection was local, the transcriptome profiling showed strong responses of zebrafish embryos exposed to PS particle, indicating a systemic response. We found several biological pathways activated which are related to an immune response in the PS exposed zebrafish larvae. Most notably the complement system was enriched as indicated by upregulation of genes in the alternative complement pathway (e.g. $c f h l 3, c f h l 4, c f b$ and $c 9$ ). The fact that complement pathway is activated indicates that plastic microparticles are integrated in immunological recognition processes. This was supported by fluorescence microscopy results, in which we observed co-localisation of neutrophils and macrophages around the PS particles. Identifying these key events can be a first building block to the development of an adverse outcome pathway (AOP). These data subsequently can be used within ecological and human risk assessment.
\end{abstract}

\section{Introduction}

As one of the first responses to the presence of xenobiotics, cells start transcribing RNA to maintain normal cellular function. Tracking this response using RNA-sequencing (RNAseq) techniques has made substantial contributions to our understanding of many biological processes triggered in organisms which are exposed to environmental contaminants. The pathways and processes activated and identified using RNAseq techniques are subsequently linked with adverse health outcomes, including development, adaptive evolution, host immune response, and stress response. The identification of target pathways of hazardous compounds allows for a better understanding of the molecular mechanisms underlying relevant adverse ecological outcomes making this area of research a primary focus in aquatic toxicology.

An excellent model organism to develop identify target pathways is the zebrafish (Danio rerio) for a variety of reasons. They offer a mapped and annotated transcriptome together with a rich repertoire of genetic, molecular and cellular manipulation tools (Strähle et al., 2012). Using these tools, molecular results suggest that the zebrafish embryo is a suitable model for systematic testing of chemicals under the European REACH initiative (Lammer et al., 2009). For this reason they represent aquatic vertebrates in toxicological assessments (Scholz et al., 2008; Stegeman et al., 2010). Moreover, zebrafish are used to investigate and answer various biomedical and toxicological research questions, including research on cancer, infectious diseases and cardiovascular disease (Spaink et al., 2013; Str \& hle et al., 2012). Up to $80 \%$ of human disease related genes can be linked to a zebrafish orthologue (Howe et al., 2013) and therefore it holds a very strong position as a screening model in between cell or tissue culture systems and higher animal models. The conservancy in the molecular targets and commonalities of

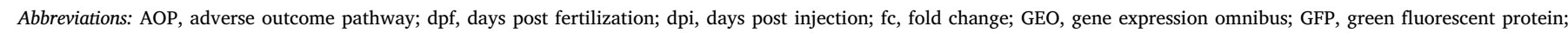

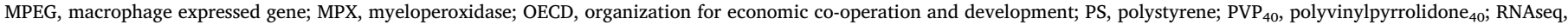
RNA sequencing; TEM, transmission electron microscopy; Tg, transgenic

* Corresponding author.

E-mail addresses: wouterveneman@gmail.com (W.J. Veneman), h.p.spaink@biology.leidenuniv.nl (H.P. Spaink), n.r.brun@cml.leidenuniv.nl (N.R. Brun), t.bosker@luc.leidenuniv.nl (T. Bosker), vijver@cml.leidenuniv.nl (M.G. Vijver). 
effect pathways will assists in the extrapolation across different species of ecological relevance. This is especially relevant when studying emergent contaminants in the environment, for which there is limited understanding through which pathway organisms are adversely affected.

One such group of contaminants are microplastics (plastic particles $<5$ mm; Andrady, 2011; Cole et al., 2011). Microplastics are intentionally added to cosmetic and household products (Chang, 2015; Fendall and Sewell, 2009) or can be formed as weathering products from larger pieces of plastics (Cole et al., 2011). As a result, there is a wide range in physico-chemical characteristics of microplastics. One of the most commonly used and produced plastics is polystyrene (PS), for example, in Europe the demand for PS in 2014 was roughly 3,5 million tons (PlasticsEurope, 2015). For this reason PS particles are frequently used as model particle to study the impact and uptake of microplastics in organisms (Besseling et al., 2013; Cole et al., 2013; Farrell and Nelson, 2013). To date, molecular responses induced by plastic particles in aquatic vertebrate species are unexplored, even though there is an urgent need to develop these pathways for highly relevant environmental compound groups such as the microplastics.

Since little is known on the frequency and consistency of uptake of particles across epithelial membranes (Skjolding et al., 2017), our study aimed to perform the first pathway analysis to investigate the effects of PS particles delivered inside zebrafish (Danio rerio) during early developmental stages. Our first objective was to understand if and to what extent migration and biodistribution of injected fluorescently labelled PS particles throughout zebrafish embryos occurred at different stages of development. Our second objective was to identify affected pathways and processes due to the presence of these particles using RNAseq. We determined biodistribution by imaging and conducted time series analyses on their transcriptomes. The transcriptomes were subsequently probed to seek pathways and processes activated, and link to potential adverse health outcomes.

\section{Material and methods}

\subsection{Particle characterisation}

Polystyrene (PS) particles (PS; nominal size $700 \mathrm{~nm}$ were purchased from Corpuscular Inc (103125-05,US). These particles are internally dyed with Nile Red to prevent dye leaching into aqueous media. The PSparticle solutions were prepared with purified water (Milli-Q) and sonicated before every use. Transmission electron microscopy (TEM, H7500 , Hitachi, Japan) was performed to verify particle size. The agglomeration behaviour at two time points (at $0,24 \mathrm{~h}$ ) of PS particles was tracked using dynamic light scattering (DLS). Also the zeta potential was determined, giving additional information of the agglomeration behaviour of PS particles in egg water.

\subsection{Zebrafish husbandry}

Zebrafish were handled in compliance with animal welfare regulations and maintained according to standard protocols (http:// ZFIN.org). Mixed egg clutches from the wildtype ABxTL, Tg(bactin:HrasEGFP VU119) (Cooper et al., 2005), Tg(mpx:EGFP) (Lawson and Weinstein, 2002a) or $\operatorname{Tg}$ (mpeg1:EGFP) $^{\text {gl22 }}$ (Ellett et al., 2011) strain were collected for the experiment. Fertilized eggs were selected at 2-8 cell stage and grown at $28{ }^{\circ} \mathrm{C}$ in egg water $\left(60 \mu \mathrm{g} \mathrm{mL}{ }^{-1}\right.$ Instant ocean sea salt, Sera Marin). The egg water was refreshed every $24 \mathrm{~h}$. All work was done under approval number of the "Netherlands Food and
Consumer Product Safety Authority': 10612. As only early life stage zebrafish were used, no specific additional project authorization was needed.

\subsection{Biodistribution of PS particles}

The PS particles were injected in the yolk of the embryos to increase the likelihood of uptake within the zebrafish larvae. Previous research has shown that this injection technique results in reproducible exposure of injected materials (such as microbes or cancer cells) inside the zebrafish embryos and larvae (Spaink et al., 2013). Therefore we followed the protocols published in Nature Methods (Spaink et al., 2013) as done for the development of drugs for cancer and microbial related diseases. To determine the importance of developmental stage on particle migration two time points in development were chosen for injections in the yolk: the blastula stage (between 16 and 128 cell stage) and the long-pec stage ( 2 days post fertilization, dpf) as determined by morphological criteria (Kimmel et al., 1995). At each stage, $1 \mathrm{~nL}$ of $4 \%$ polyvinylpyrrolidone 40 $\left(\mathrm{PVP}_{40}\right.$; Calbiochem, US) containing $5 \mathrm{mg} \mathrm{mL} \mathrm{m}^{-1}$ of Nile red fluorescently labelled PS particles (103125-05, Corpuscular inc. US) were injected into the yolk sac of embryos $(n=150)$. Transmission electron microscopy (TEM; JEOL 1010; JEOL Ltd., Japan) analysis confirmed an average diameter of $710 \pm 23$ (SD) $\mathrm{nm}$ of these PS particles (Additional file 1). Injections were controlled using a Leica M50 stereomicroscope together with a FemtoJet microinjector (Eppendorf, Germany) and a micromanipulator with pulled and bevelled micro capillary needles. Control embryos ( $\mathrm{n}=50$ ) were mock-injected with $1 \mathrm{~nL}$ of $\mathrm{PVP}_{40}$ only.

Throughout the paper, for developmental stages within the chorion (until $2 \mathrm{dpf}$ ) the term "embryo" is used and for later stages the term "larva". Migration and biodistribution of injected PS particle in embryos and larvae were examined and imaged daily until $5 \mathrm{dpf}$ using a fluorescence stereo microscope (MZ 205 FA, Leica, Germany). If not hatched at $3 \mathrm{dpf}$, embryos were manually dechorionaed for comparative imaging. To optimize visualization of the biodistribution of particles inside the embryos and larvae we used the Tg(bactin:Hras-EGFP VU119) strain which expresses membrane-targeted green fluorescent protein (GFP). Embryos and larvae were kept under anaesthesia $(0.02 \%$ buffered 3-aminobenzoic acid ethyl ester; Tricaine, Sigma, The Netherlands) in egg water during imaging. The image processing package Fiji (Schindelin et al., 2012) was used for processing and analysis of the images.

\subsection{Transcriptomic analyses}

Based on the biodistribution data, injection at the long-pec stage (2 dpf) was chosen for RNAseq. ABxTL larvae ( $n=150$ embryos) in the long-pec stage were injected with $1 \mathrm{~nL}$ of $4 \% \mathrm{PVP}_{40}$ containing red fluorescently labelled PS particles into the yolk (as described above). Control embryos $(n=50)$ were mock-injected with $1 \mathrm{~nL}$ of $\mathrm{PVP}_{40}$ only. Sampling was performed at 1 and 3 days post injection (dpi) aiming to find direct and late transcriptome responses. At 1 and $3 \mathrm{dpi}$, ten embryos or larvae, respectively, showing distribution of PS particles throughout the body were pooled and three samples per group collected (representing biological triplicates). For the mock-injection biological duplicates were used. All samples were snap frozen in liquid nitrogen, and stored at $-80^{\circ} \mathrm{C}$ for RNA isolation later on.

RNA isolation was performed as described in Veneman et al. (2013). Briefly, a total of $3 \mu \mathrm{g}$ of RNA was used to construct RNAseq libraries using the Illumina TruSeq RNA Sample Preparation Kit v2 (Illumina Inc., San Diego, USA). In the manufacturer's instructions two 
modifications were made. Firstly, in the adapter ligation step $1 \mu \mathrm{l}$ instead of $2.5 \mu \mathrm{l}$ adaptor was used. Secondly, in the library size selection step the library fragments were isolated with a double Ampure XP purification with a $0.7 \times$ beads to library ration. The resulting mRNAseq library was sequenced using an Illumina HiSeq2500 instrument according to the manufacturer's description with a read length of $2 \times 50$ nucleotides. Image analysis and base calling was done by the Illumina HCS version 2.2.38, RTA version 1.16.61.

\subsection{Data analysis}

The GeneTiles server (www.genetiles.com) was used for data processing, quantification and visualization of the RNAseq data as described in Veneman et al. (2014). Briefly, Bowtie2 (Langmead and Salzberg, 2012) was used to align the reads from the fastq file to the zebrafish genome (GRCz10). Reads were randomly distributed upon multiple hits (default settings) in the generated SAM file. Samtools (Li et al., 2009) converts and compress the SAM file into a BAM file. A python script containing HTseq and pysam (Anders et al., 2015) allowed read count within a gene for reads that partially fall within the gene exon and intron region. Statistical analysis was performed using DESeq. Reads were normalized using a scaling factor, computed as the median of the ratio, for each gene and of its read count of the geometric mean across samples. The variance and average of the measurement is compared to the control and expressed as a $P$ value calculated by the dispersion per gene. The data has been deposited in the NCBI GEO database under accession number: GSE77755.

Three different open-source software packages were used for additional statistical analysis and/or pathway enrichment: Pathvisio 3 (Pico et al., 2008) to extract enriched biological pathways, STRING (Szklarczyk et al., 2015) to assess functional enrichment of proteinprotein interactions and g:Profiler (Reimand et al., 2011, 2007) with the g:Cocoa function for functional profiling of differentially expressed of gene lists. For the complement pathway analysis the human (Homo sapiens) complement and coagulase cascades pathway from Wikipathways has been modified to zebrafish orthologues, since there are hitherto no complement genes annotated for zebrafish.

\section{Results and discussion}

\subsection{Particle characteristics}

The size and shape of PS particles were further confirmed by transmission electron microscopy (Fig. S1). No agglomeration of the particles over time were found (DLS results not shown), and also the zeta potential was stable and did not change over time.

\subsection{Particle migration and distribution in blastula stage injected eggs}

After injection of PS particles into the yolk of blastula stage (16-128 cell stage) embryos, more than $95 \%$ of the injected test organisms did not show signs of developmental defects. Most particles tended to stay at the yolk injection site, and in only $12.5 \%$ of the embryos at $5 \mathrm{dpi}$ migration away from the injection site occurred. Specifically, when the yolk started to be depleted at 3-4 dpi, some larvae showed signs of accumulation of particles around the heart region and within the blood stream (Fig. 1). This is in line with previous results in our group, showing a low percentage (0-10\%) of embryos with distributed micro sized $(2-10 \mu \mathrm{m}$ size range) PS particles after yolk injection (unpublished data). In comparison, in the blastula stage essential elements such as vitamins are transferred from the yolk to the developing embryo
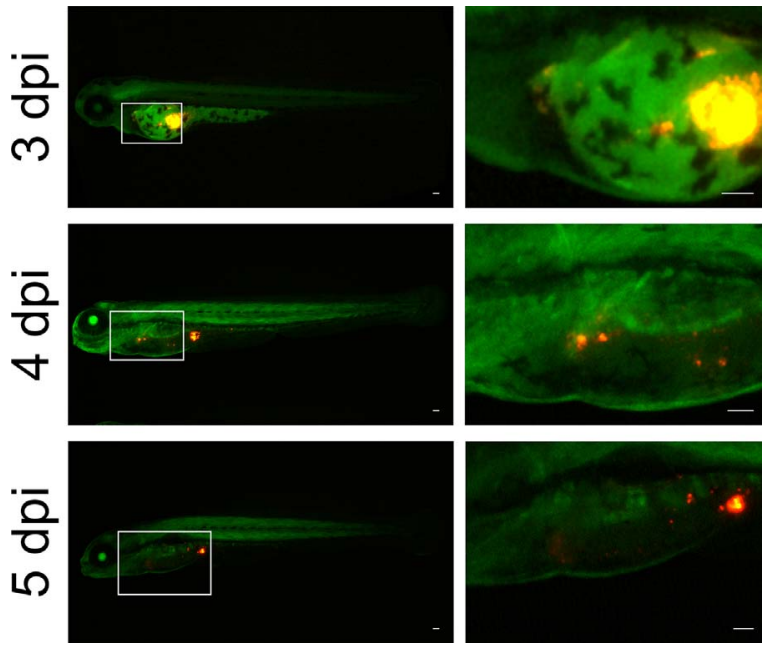

Fig. 1. Detailed overview of Tg(bactin:Hras-EGFP VU119) zebrafish larvae injected between 16 and 128 cell stage with red fluorescently labelled polystyrene (PS) particles. The regions of the images on the right are indicated by the white box on the left, showing the PS particles close to the heart region ( $3 \mathrm{dpi}, 4 \mathrm{dpi}, 5 \mathrm{dpi}$ ) or already migrated away from the yolk injection site $(5 \mathrm{dpi})$. Scale bars are $100 \mu \mathrm{m}$. (For interpretation of the references to colour in this figure legend, the reader is referred to the web version of this article.)

at a significant higher rate of $88 \%$ (Surai et al., 2014). In addition, various species of bacteria and some types of cancer cells are also much more effectively transferred from the yolk to the developing embryo (Spaink et al., 2013). Overall this indicates a rather low percentage of distribution of PS particles after injection at the blastula stage.

Waterborne exposure of zebrafish embryos and larvae to PS particles is an environmental relevant uptake path. Within this study we have not addressed this route, because previous studies reported for various different sizes $(25-700 \mathrm{~nm})$ PS particles that the internalization is low, estimated to be less than $10 \%$ (Van Pomeren et al. in press). The majority of the PS particles remained in the chorion or adsorbed to the zebrafish epithelium (both skin and gut epithelium) depending on their developmental stage. This $<10 \%$ absorption means that $>90 \%$ was not internalized, leading to variable internal concentrations which hampers identification of affected pathways and processes due to the presence of these particles. Dietary uptake of PS particles in fish is expected to be a factor 10 higher (Skjolding et al., 2017) but was beyond our current approach of short term (5 days) exposure. It is likely that waterborne exposure results in a more or less similar biodistribution especially over time.

\subsection{Particle migration and distribution in 2 day old injected embryos}

When injecting PS particles into the yolk of 2 dpf embryos, the percentage of larvae in which there was migration of microplastics to the bloodstream increased to $26.4 \%$ at 4 dpi (Fig. 2). At 2 dpf the embryos already have a vascular system developed and the yolk to embryo ratio is smaller than in earlier stages; both factors may explain the increased spreading of PS observed. In embryos with particle migration no uptake into tissues was observed, and particles remained within the vascular system. After injection, no damage was observed to the Duct of Cuvier, a vessel that spreads from the yolk sac towards the heart (Lawson and Weinstein, 2002b) and there was no indication that the PS particles leached into the Duct of Cuvier, indicating that PS 

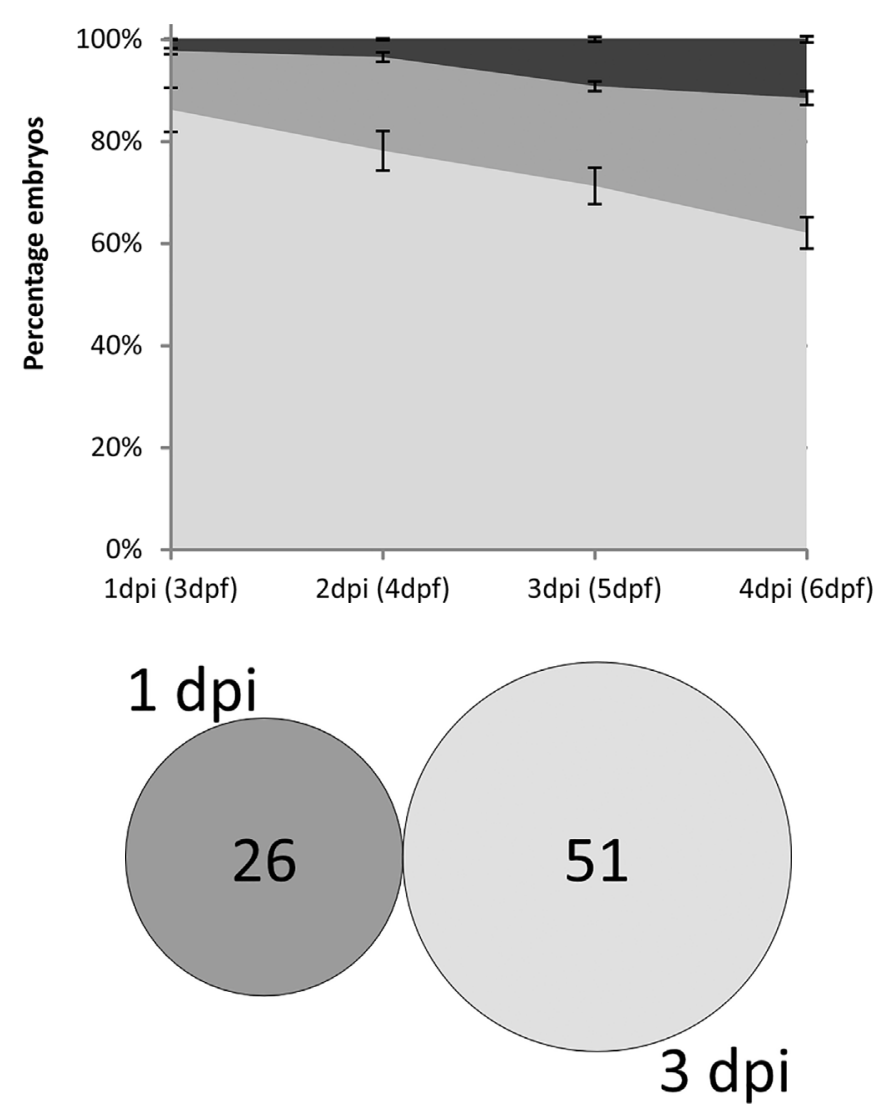

Fig. 3. No overlapping expression at different time points. Venn diagram showing the differentially expressed genes at 1 and 3 dpi in zebrafish embryos and larvae injected with polystyrene particles at 2 days post fertilization. (fc $>=2$ or $<=-2$ and $P$ value $<$ $=0.05$ ).

particles moved solely through the blood stream and got locally stuck in smaller vessels (as observed during live imaging).

\subsection{Transcriptome analysis}

Injection of PS particles caused significant changes in transcriptomic profiles of zebrafish larvae. At 1 dpi we found a group of 81 genes differentially expressed (fc: $>2$ or $<-2$ and $P<0.05$ ) in the PS particle injected embryos as compared to the non-injected group minus the mock control, while 55 genes were also differentially expressed in the mock-injected control group as compared to the non-injected control. This led to a group of 26 genes which were differentially expressed at $1 \mathrm{dpi}$ in the PS particle injected embryos (Fig. 3). At 3 dpi 57 genes were differentially expressed in the PS particle injected larvae, while only 6 genes were differentially expressed in the mock-injected group, as compared to the non-injected. This resulted in 51 differentially expressed genes at $3 \mathrm{dpi}$ (Fig. 3). This reduction between 1 and $3 \mathrm{dpi}$ in differently expressed genes in the mock-injected larvae can be explained due to minor tissue damage associated with the injection (Cocchiaro and Rawls, 2013), resulting in increased differentially expressed genes in the mock-injected group at $1 \mathrm{dpi}$ and subsequent recovery at $3 \mathrm{dpi}$. Interestingly, there were no overlapping particle-specific genes that were differentially expressed at 1 and 3 dpi. An overview off all differentially expressed genes grouped using STRING is shown in Fig. 4.
Fig. 2. Percentage of zebrafish larvae with polystyrene particles distributed away from the yolk injection site at different time points after injection at $2 \mathrm{dpf}(\mathrm{n}=87)$.

\author{
dead \\ $\square$ spreading \\ no-spreading
}

At $3 \mathrm{dpi}$, with reduced tissue damage expression, we found several processes and pathways enriched related to the complement system (Fig. 5). The complement system is composed of about 30 proteins, which, after activation by antigens, can cause either the formation of a hollow cylinder complex which can penetrate a pathogenic cell causing cell death by extracellular influx, or it results in coating of the pathogen for opsonization for phagocytic cell uptake (Jovanovic and Palic, 2012). In fish the complement system can be activated by three pathways: the classical, alternative or lectin pathways (Janeway et al., 2001; Whyte, 2007). Based on initial analysis using GeneTiles, genes including $c f b$, cfh, c3a.2, c3a.3, c3a.6 and $c 9$ were induced, indicating that predominately the alternative pathway acts first. The alternative pathway is activated when there are pathogens without the presence of antibodies (Janeway et al., 2001; Whyte, 2007), which is the case for PS particles. Similar to our study, the complement system is activated in mice exposed to nanomedicines and carbon nanotubes (Moghimi et al., 2010). Interestingly we only observe upregulation of the alternative pathway, while with nanomedicines and carbon nanotubes both the classical and alternative pathways are activated (Moghimi et al., 2010). Our results show that although PS particles do not have any corresponding receptors and hence need to be tagged by the complement system to be cleared from the body, the particles are recognized by the immune system. Our results are supported with imaging data: there was an overlap of PS particles and neutrophils (Fig. 6) and macrophages (Fig. 7). In approximately $26 \%$ of the embryos the red PS particles overlap with neutrophils (green signal, MPX) and macrophages (green signal, MPEG) as shown in Figs. 6 and 7, respectively.

In the work by Zhang and Cui (2014) the current status of identification of the complement components in zebrafish based on the comparison with the mammalian system components is reported. It showed evidence that all the homologs of the mammalian complement fundamental components are present in zebrafish, as revealed by the phylogenetic analysis. Unfortunately this complement component pathway was not available for zebrafish pathway analysis which made comparison rather difficult. However $80 \%$ of human disease related genes can be linked to a zebrafish orthologue (Howe et al., 2013). Therefore we used the human pathway of complement and coagulase cascades (Wikipathways), and modified this to zebrafish orthologues. In our case, 8 zebrafish genes were linked to the human genes (Fig. 8: red squares). Since zebrafish at larval stage have no adaptive immune system (Meijer and Spaink, 2011), we only described the host response of the innate immune system. In vertebrates models and humans it was shown that the complement system is activated after exposure to lipidbased nanoparticles (Khanna et al., 2015). However, innate immune 


\begin{tabular}{|c|c|c|c|c|}
\hline source & $\begin{array}{l}\text { term name } \\
\text { Gene Ontology (Biological process) }\end{array}$ & $\begin{array}{l}\text { n. of } \\
\text { term } \\
\text { genes }\end{array}$ & $\begin{array}{l}\text { corrected } \\
p \text {-value }\end{array}$ & $\begin{array}{l}\vec{\omega} \omega \\
\text { 응. 음. }\end{array}$ \\
\hline $\mathrm{BP}$ & 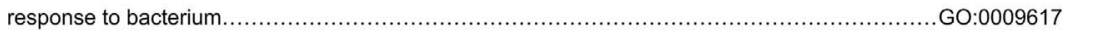 & 119 & $1.16 \mathrm{e}-02$ & \\
\hline $\mathrm{BP}$ 든 & response to gonadotropin........................ & 7 & $1.07 e-02$ & 2 \\
\hline $\mathrm{BP}$ & cellular response to gonadotropin stimulus... & 7 & $1.07 e-02$ & 2 \\
\hline $\mathrm{BP}$ & multicellular organismal response to stress................. & 12 & $4.11 e-02$ & 2 \\
\hline $\mathrm{BP}$ 든 & response to organophosphorus................ & 12 & $3.37 e-02$ & 2 \\
\hline $\mathrm{BP}$ & 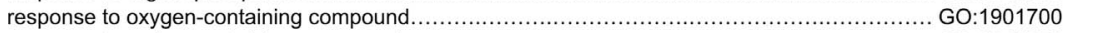 & 180 & $8.47 e-03$ & 4 \\
\hline $\mathrm{BP}$ & response to purine-containing compound... & 12 & $3.37 e-02$ & 2 \\
\hline $\mathrm{BP}$ & response to CAMP...................................... & 12 & $3.37 e-02$ & 2 \\
\hline $\mathrm{BP}$ & cellular response to lipid.. & 45 & $3.49 e-02$ & 3 \\
\hline $\mathrm{BP}$ & response to steroid hormone..................... & 44 & $3.26 \mathrm{e}-02$ & 3 \\
\hline $\mathrm{BP}$ & response to estrogen.......................... & 40 & $2.44 \mathrm{e}-02$ & 3 \\
\hline BP & cellular response to organic cyclic compound......... & 61 & $1.25 \mathrm{e}-02$ & 3 \\
\hline BP & cellular response to steroid hormone stimulus.... & 36 & $1.77 \mathrm{e}-02$ & 3 \\
\hline BP & cellular response to estrogen stimulus...................... & 33 & $1.35 e-02$ & 3 \\
\hline $\mathrm{BP}$ & cellular response to CAMP........................... & 7 & $1.07 e-02$ & 2 \\
\hline source & $\begin{array}{l}\text { term name } \\
\text { Gene Ontology (Molecular function) }\end{array}$ & $\begin{array}{l}\text { n. of } \\
\text { term } \\
\text { genes }\end{array}$ & $\begin{array}{l}\text { corrected } \\
p \text {-value }\end{array}$ & $\begin{array}{l}\overrightarrow{0} \omega \\
\text { 음. 응. }\end{array}$ \\
\hline MF 듣 & nucleic acid binding transcription factor activity.. & 389 & $1.26 \mathrm{e}-02$ & 5 \\
\hline MF & transcription factor activity, sequence-specific DNA binding.... & 389 & $1.26 e-02$ & 5 \\
\hline source & $\begin{array}{l}\text { term name } \\
\text { Human Phenotype Ontology }\end{array}$ & $\begin{array}{l}\text { n. of } \\
\text { term } \\
\text { genes }\end{array}$ & $\begin{array}{l}\text { corrected } \\
p \text {-value }\end{array}$ & $\begin{array}{l}\overrightarrow{0} \omega \\
\text { 음. 음. }\end{array}$ \\
\hline $\mathrm{hp}$ 듣 & $\ldots \ldots \ldots \ldots . \mathrm{HP}: 0000123$ & 33 & $1.02 \mathrm{e}-07$ & 6 \\
\hline hp & Abnormality of the nephron.................................. & 148 & $2.93 e-05$ & 7 \\
\hline hp & 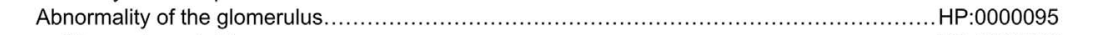 & 102 & $2.12 \mathrm{e}-06$ & 7 \\
\hline hp & Glomerulonephritis............................. & 24 & $1.25 \mathrm{e}-08$ & 6 \\
\hline hp & Membranoproliferative glomerulonephritis................ & 11 & $3.03 e-04$ & 3 \\
\hline hp & 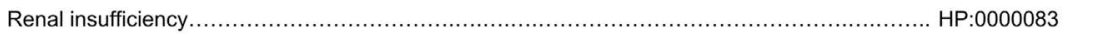 & 279 & $2.07 e-02$ & 6 \\
\hline $\mathrm{hp}$ & Recurrent bacterial infections......................... & 83 & $8.66 \mathrm{e}-04$ & 5 \\
\hline $\mathrm{hp} \mathrm{듣}$ & Abnormality of humoral immunity................. & 158 & $4.63 e-05$ & 77 \\
\hline hp & 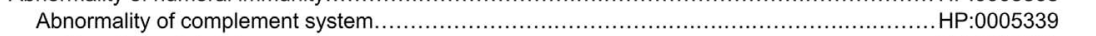 & 34 & $6.57 e-10$ & 7 \\
\hline hp & 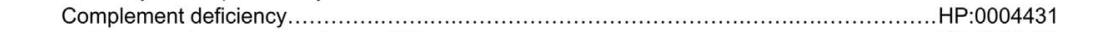 & 28 & $1.45 \mathrm{e}-10$ & 7 \\
\hline hp & 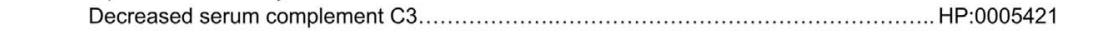 & 7 & $6.44 \mathrm{e}-05$ & 3 \\
\hline source & $\begin{array}{l}\text { term name } \\
\text { Biological pathways (KEGG) }\end{array}$ & $\begin{array}{l}\text { n. of } \\
\text { term } \\
\text { genes }\end{array}$ & $\begin{array}{l}\text { corrected } \\
p \text {-value }\end{array}$ & $\begin{array}{l}\overrightarrow{\mathrm{o}} \omega \\
\text { 음. 음. }\end{array}$ \\
\hline ke & Phagosome.................... & 139 & $1.93 e-02$ & 3 \\
\hline ke & Degradation of aromatic compounds......... & 4 & $4.52 \mathrm{e}-02$ & 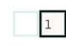 \\
\hline source & $\begin{array}{l}\text { term name } \\
\text { Biological pathways (Reactome) }\end{array}$ & $\begin{array}{l}\text { n. of } \\
\text { term } \\
\text { genes }\end{array}$ & $\begin{array}{l}\text { corrected } \\
\text { p-value }\end{array}$ & $\begin{array}{l}\overrightarrow{\mathrm{o}} \omega \\
\text { 음. 음. }\end{array}$ \\
\hline re चृ & Complement cascade....................... & 24 & $3.83 e-09$ & 5 \\
\hline re & 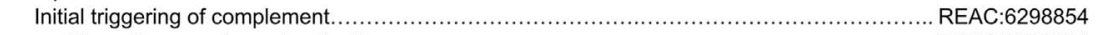 & 13 & $1.09 \mathrm{e}-07$ & 4 \\
\hline re & 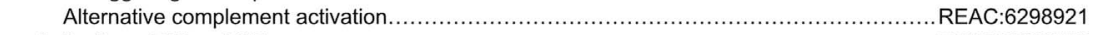 & 6 & $2.60 \mathrm{e}-06$ & 3 \\
\hline re & 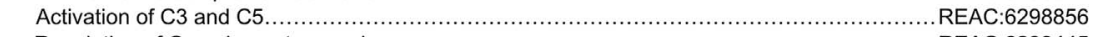 & 6 & $2.60 \mathrm{e}-06$ & 3 \\
\hline re & Regulation of Complement cascade...... & 16 & $1.39 \mathrm{e}-07$ & 4 \\
\hline
\end{tabular}

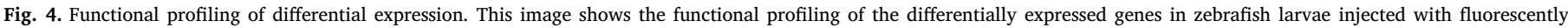

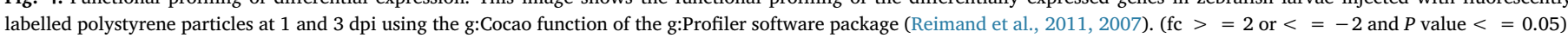
The numbers in the boxes below $1 \mathrm{dpi}$ and $3 \mathrm{dpi}$, respectively, indicate the enriched gene list, the colours intensity of red denotes the strength of enrichment.

responses to PS microparticles as we show here has to our knowledge not been documented yet. Uncontrolled complement activation likely leads to tissue damage and activation of down-stream inflammatory processes (Ricklin and Lambris 2013). However, the exact mechanism of how these complement proteins mediate nanotoxicity has not yet been elucidated (Zolnik et al., 2010).

The gene ontology shows several term IDs expressed at 1 and $3 \mathrm{dpi}$ related to 'response', e.g. response to bacterium, gonadotropin, organophosphorus, oxygen-containing compound, purine-containing compound, steroid hormone and organic cyclic compound (Figs. 4 and 5). This indicates a broad host response against microplastic particles. Furthermore, using Pathvisio 3 we performed statistical analysis on the expression dataset in order to find enriched biological pathways at 1 and $3 \mathrm{dpi}$. At both days the pathway for nuclear receptors in lipid metabolism and toxicity was significantly enriched, and at 3 dpi the oxidative stress pathway (Table 1). Oxidative stress is a well-recognized mode of action of various nanoparticles (Manke et al., 2013; Sarkar et al., 2014). Our results indicate that even though spreading of particles is limited and local (based on the imaging pictures), this leads to innate immune responses of a systemic nature (based on imaging and transcriptomic data). Exposure to the PS particles enriched the complement system which showed that the immunological recognition process is active. These molecular initiating events and pathways have potentials to become early warning markers of long-term health 


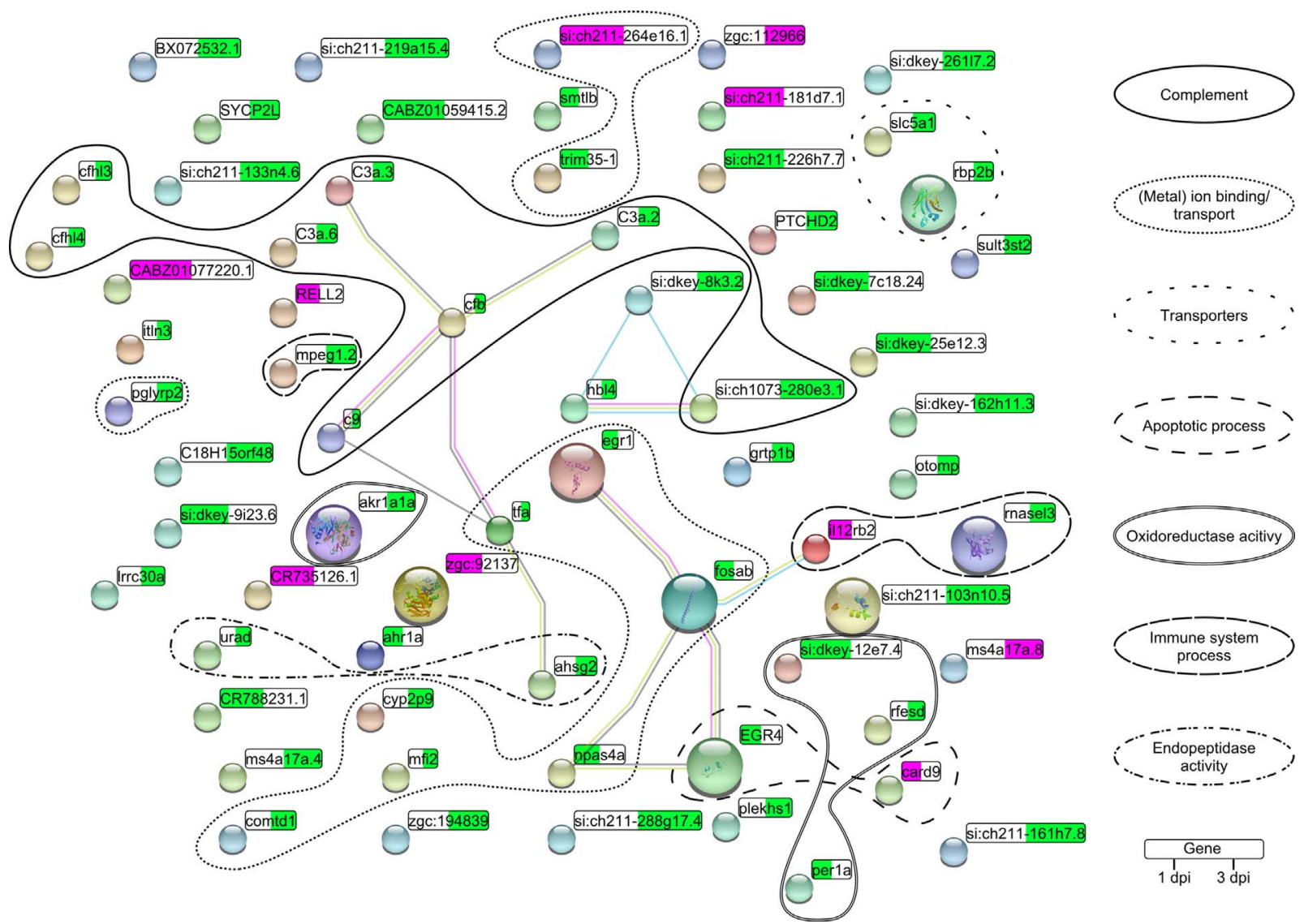

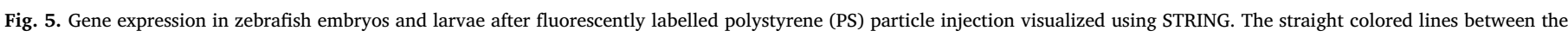

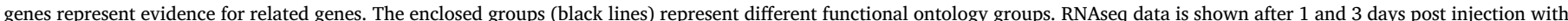

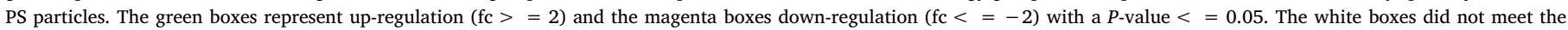
criteria. (For interpretation of the references to colour in this figure legend, the reader is referred to the web version of this article.)

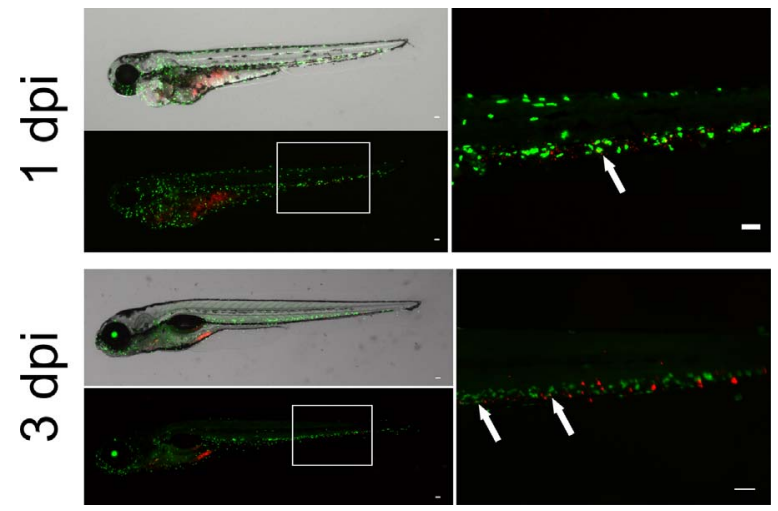

Fig. 6. Uptake of polystyrene particles by neutrophils. Overview of $\operatorname{Tg}(m p x: E G F P)$ zebrafish embryos injected at $2 \mathrm{dpf}$ into the yolk with red fluorescently labelled polystyrene (PS) particles at $1 \mathrm{dpi}$ and $3 \mathrm{dpi}$. These images represent the distributed PS particles away from the injection site (yolk) in the heart region and the tail area. The regions of the images on the right are indicated by the white box on the left. The overlap of the neutrophils (green) and PS particles (red) signal is indicated by the white arrows. Scale bars are $100 \mu \mathrm{m}$. (For interpretation of the references to colour in this figure legend, the reader is referred to the web version of this article.)

impacts. Due to conservancy of certain effect pathways across species the pathways identified here can be of importance for different ecological levels. Within risk assessment, the identification of molecular key events (KE) and toxicological pathways are stepping stones to develop

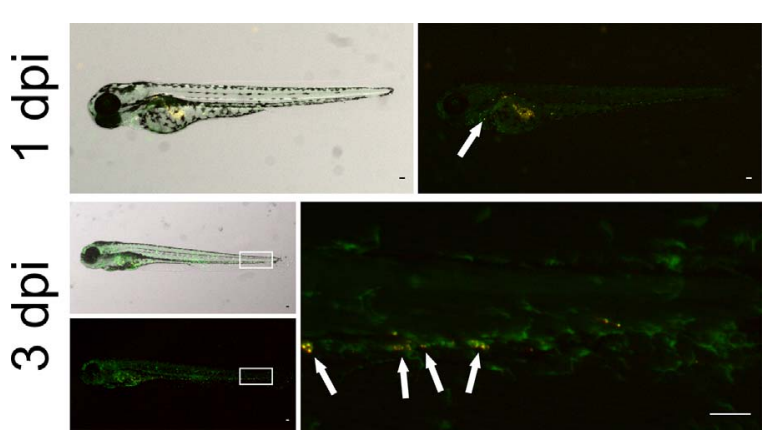

Fig. 7. Uptake of polystyrene particles by macrophages. Overview of $\operatorname{Tg}(m p e g 1: E G F P)^{\text {gl22 }}$ zebrafish embryos injected at $2 \mathrm{dpf}$ into the yolk with fluorescently labelled polystyrene (PS) particles at $1 \mathrm{dpi}$ and $3 \mathrm{dpi}$. These images represent the distributed PS particles away from the injection site (yolk) in the heart region and the tail area. The regions of the images on the right are indicated by the white box on the left. The overlap of the macrophages (green) and PS particles (red) signal is indicated by the white arrows. Scale bars are $100 \mu \mathrm{m}$. (For interpretation of the references to colour in this figure legend, the reader is referred to the web version of this article.)

an Adverse Outcome Pathway (AOP) as initiated in 2012 under The Organization for Economic Co-operation and Development (OECD) guidelines. AOPs can be used for human and ecological risk assessment of drugs (Lee et al., 2015; Wink et al., 2014) or chemicals (Ankley et al., 2010; Ganguly et al., 2009). 


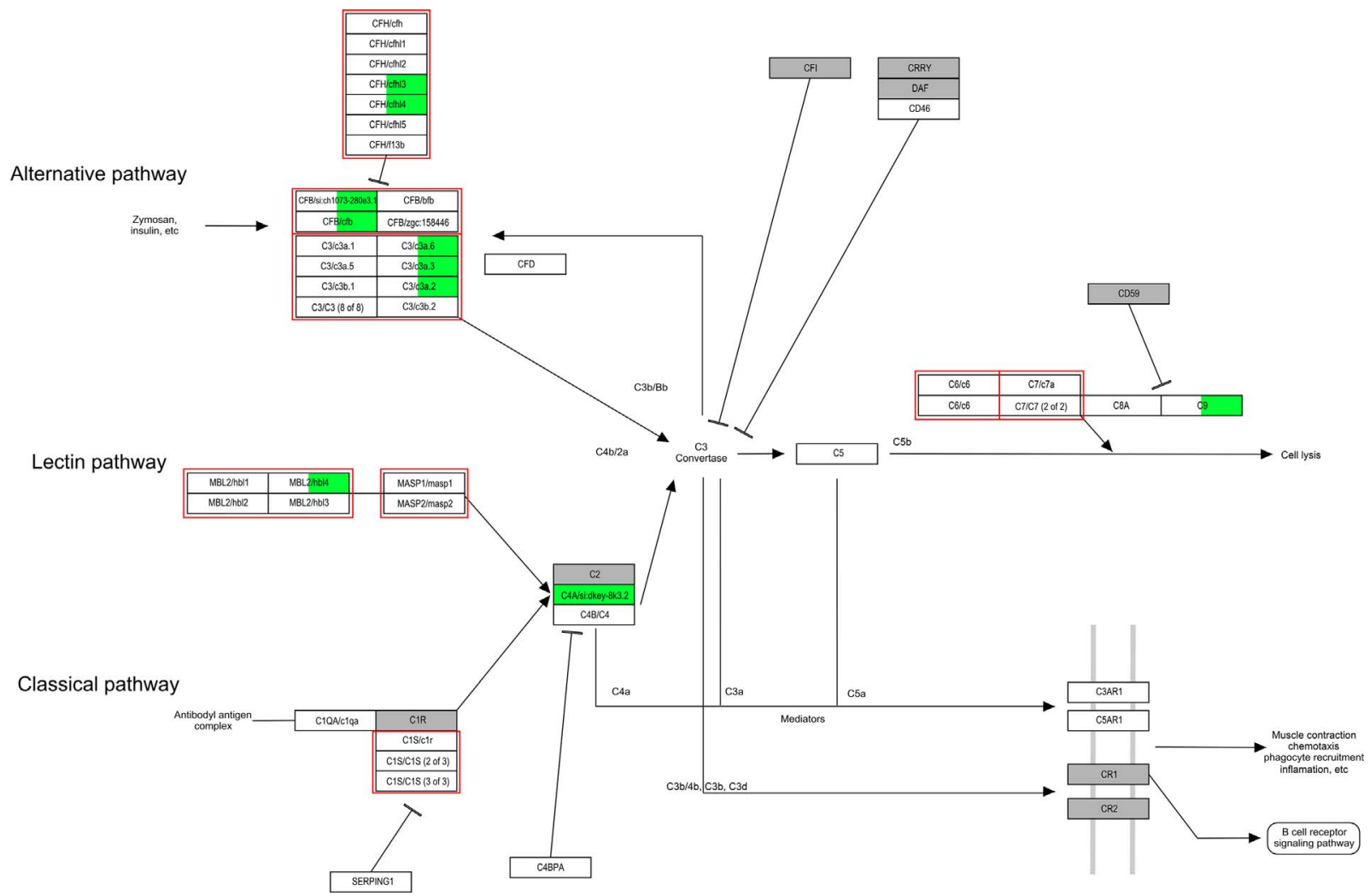

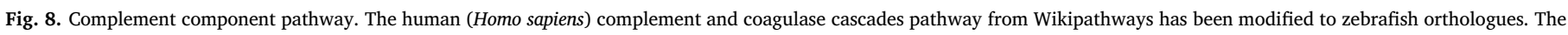

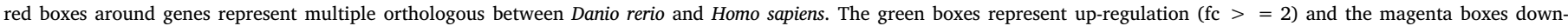

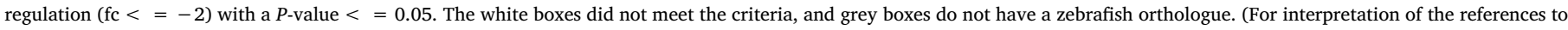
colour in this figure legend, the reader is referred to the web version of this article.)

Table 1

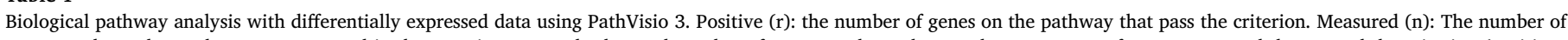

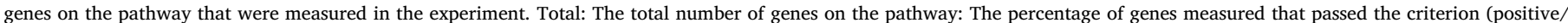

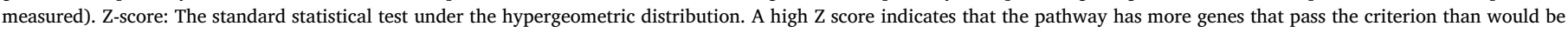

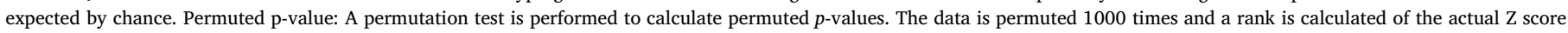
compared to the permuted Z Scores. Pathways with a permuted $p$-value $<=0.05$ are significant. (Criterion: $\mathrm{fc}>=2$ or $<=-2$ and $P$ value $<=0.05$ ).

\begin{tabular}{|c|c|c|c|c|c|c|c|}
\hline & Pathway & Positive (r) & Measured (n) & Total & $\%$ & Z Score & P-value (permuted) \\
\hline \multirow[t]{6}{*}{1 dpi } & Nuclear receptors in lipid metabolism and toxicity & 4 & 12 & 26 & $33.33 \%$ & 7.66 & 0 \\
\hline & Striated Muscle Contraction & 4 & 21 & 30 & $19.05 \%$ & 5.51 & 0.001 \\
\hline & ACE Inhibitor Pathway & 2 & 6 & 12 & $33.33 \%$ & 5.41 & 0.001 \\
\hline & Osteoclast & 1 & 5 & 12 & $20.00 \%$ & 2.83 & 0.019 \\
\hline & Regulation of Actin Cytoskeleton & 5 & 84 & 113 & $5.95 \%$ & 2.57 & 0.009 \\
\hline & Pathway & Positive (r) & Measured (n) & Total & $\%$ & Z Score & P-value (permuted) \\
\hline \multirow[t]{6}{*}{$3 \mathrm{dpi}$} & ACE Inhibitor Pathway & 2 & 6 & 12 & $33.33 \%$ & 6.79 & 0 \\
\hline & Nuclear receptors in lipid metabolism and toxicity & 2 & 12 & 26 & $16.67 \%$ & 4.6 & 0.001 \\
\hline & Peptide GPCRs & 3 & 34 & 41 & $8.82 \%$ & 3.8 & 0.002 \\
\hline & Glycolysis and Gluconeogenesis & 2 & 25 & 38 & $8.00 \%$ & 2.89 & 0.015 \\
\hline & GPCRs, Class C Metabotropic glutamate, pheromone & 1 & 8 & 11 & $12.50 \%$ & 2.73 & 0.038 \\
\hline & Oxidative Stress & 1 & 14 & 23 & $7.14 \%$ & 1.88 & 0.028 \\
\hline
\end{tabular}

\section{Conclusions}

Our results provide insights in the biodistribution and response pathways of zebrafish embryos and larvae exposed internally to PS particles. Although biodistribution of PS particles was relatively low, the transcriptome analysis showed systemic immune responses of zebrafish when exposed to PS particle. The transcriptomic data demonstrated that exposure to PS particles can result in activation of the complement system which indicates that PS particles are integrated in immunological recognition process. At all sampling time points, we found the nuclear receptors in lipid metabolism and toxicity pathway significantly enriched, and the oxidative stress pathway only at $3 \mathrm{dpi}$ significantly expressed. This data on key events (KEs) can be used to further investigate AOPs for microplastics, a group of relatively unexplored compounds. Such microplastics are widely distributed in aquatic environments, and therefore our results are highly relevant to environmental and human risk assessment of plastic particles.

\section{Consent for publication}

Not applicable. 


\section{Availability of data and material}

All RNAseq data is submitted under GEO database accession number: GSE77755.

Reviewer access link: http://www.ncbi.nlm.nih.gov/geo/query/ acc.cgi?token = yzineiuezjijfun\&acc $=$ GSE77755.

\section{Competing interests}

The authors declare that they have no competing interests.

\section{Funding}

MGV was funded by NWO VIDI Project (project number 864.13.010), and MGV and TB were funded by the Gratama Foundation of the Leiden University Fund (project number 2015-08).

\section{Authors' contributions}

WJV designed and performed experiments, and analyzed the data. HPS and MGV conceived and supervised the study. WJV wrote the first version of the manuscript. All authors assisted with writing and editing of the manuscript and approved the final version.

\section{Acknowledgements}

We thank Davy de Witt and Ulrike Nehrdich for fish caretaking, Gerda Lamers for help with the transmission electron microscopy and other colleagues from Leiden University for helpful discussions.

\section{Appendix A. Supplementary data}

Supplementary data associated with this article can be found, in the online version, at http://dx.doi.org/10.1016/j.aquatox.2017.06.014.

\section{References}

Anders, S., Pyl, P.T., Huber, W., 2015. HTSeq-A Python framework to work with highthroughput sequencing data. Bioinformatics 31, 166-169. http://dx.doi.org/10. 1093/bioinformatics/btu638.

Andrady, A.L., 2011. Microplastics in the marine environment. Mar. Pollut. Bull. 62, 1596-1605. http://dx.doi.org/10.1016/j.marpolbul.2011.05.030.

Ankley, G.T., Bennett, R.S., Erickson, R.J., Hoff, D.J., Hornung, M.W., Johnson, R.D., et al., 2010. Adverse outcome pathways: a conceptual framework to support ecotoxicology research and risk assessment. Environ. Toxicol. Chem. 29, 730-741. http://dx.doi.org/10.1002/etc.34.

Besseling, E., Wegner, A., Foekema, E.M., van den Heuvel-Greve, M.J., Koelmans, A.A., 2013. Effects of microplastic on fitness and PCB bioaccumulation by the lugworm Arenicola marina (L.). Environ. Sci Technol. 47, 593-600. http://dx.doi.org/10.1021/ es302763x.

Chang, M., 2015. Reducing microplastics from facial exfoliating cleansers in wastewater through treatment versus consumer product decisions. Mar. Pollut. Bull. 101, 330-333. http://dx.doi.org/10.1016/j.marpolbul.2015.10.074.

Cocchiaro, J.L., Rawls, J.F., 2013. Microgavage of zebrafish larvae. J. Vis. Exp. 12. http:// dx.doi.org/10.3791/4434.

Cole, M., Lindeque, P., Halsband, C., Galloway, T.S., 2011. Microplastics as contaminants in the marine environment: a review. Mar. Pollut. Bull. 62, 2588-2597. http://dx.doi. org/10.1016/j.marpolbul.2011.09.025.

Cole, M., Lindeque, P., Fileman, E., Halsband, C., Goodhead, R., Moger, J., et al., 2013. Microplastic ingestion by zooplankton. Environ. Sci Technol. 47, 6646-6655. http:// dx.doi.org/10.1021/es400663f.

Cooper, M.S., Szeto, D.P., Sommers-Herivel, G., Topczewski, J., Solnica-Krezel, L., Kang, H.C., et al., 2005. Visualizing morphogenesis in transgenic zebrafish embryos using BODIPY TR methyl ester dye as a vital counterstain for GFP. Dev. Dyn. 232, 359-368. http://dx.doi.org/10.1002/dvdy.20252.

Ellett, F., Pase, L., Hayman, J.W., Andrianopoulos, A., Lieschke, G.J., 2011. mpeg1 promoter transgenes direct macrophage-lineage expression in zebrafish. Blood 117, e49-56. http://dx.doi.org/10.1182/blood-2010-10-314120. blood-2010-10-314120 [pii].

Farrell, P., Nelson, K., 2013. Trophic level transfer of microplastic: Mytilus edulis (L.) to Carcinus maenas (L.). Environ. Pollut. 177, 1-3. http://dx.doi.org/10.1016/j.envpol. 2013.01.046.

Fendall, L.S., Sewell, M.A., 2009. Contributing to marine pollution by washing your face: microplastics in facial cleansers. Mar. Pollut. Bull. 58, 1225-1228. http://dx.doi.org/ 10.1016/j.marpolbul.2009.04.025.

Ganguly, K., Upadhyay, S., Irmler, M., Takenaka, S., Pukelsheim, K., Beckers, J., et al., 2009. Pathway focused protein profiling indicates differential function for IL-1B, -18 and VEGF during initiation and resolution of lung inflammation evoked by carbon nanoparticle exposure in mice. Part. Fibre Toxicol. 6, 31. http://dx.doi.org/10.1186/ 1743-8977-6-31. (1743-8977-6-31 [pii]).

Howe, K., Clark, M.D., Torroja, C.F., Torrance, J., Berthelot, C., Muffato, M., et al., 2013. The zebrafish reference genome sequence and its relationship to the human genome. Nature 496, 498-503. http://dx.doi.org/10.1038/nature12111.

Janeway, C.A., Travers, P., Walport, M., Shlomchik, M.J., 2001. Immunobiology, 5th edition. Garland Science, New York, USA.

Jovanovic, B., Palic, D., 2012. Immunotoxicology of non-functionalized engineered nanoparticles in aquatic organisms with special emphasis on fish-review of current knowledge, gap identification, and call for further research. Aquat. Toxicol. 118, 141-151. http://dx.doi.org/10.1016/j.aquatox.2012.04.005.

Khanna, P., Ong, C., Bay, B., Baeg, G., 2015. Nanotoxicity: an interplay of oxidative stress, inflammation and cell death. Nanomaterials 5, 1163-1180. http://dx.doi.org/10. 3390/nano5031163.

Kimmel, C.B., Ballard, W.W., Kimmel, S.R., Ullmann, B., Schilling, T.F., 1995. Stages of embryonic development of the zebrafish. Dev. Dyn. 203, 253-310. http://dx.doi.org/ 10.1002/aja.1002030302.

Lammer, E., Carr, G.J., Wendler, K., Rawlings, J.M., Belanger, S.E., Braunbeck, T., 2009. Is the fish embryo toxicity test (FET) with the zebrafish (Danio rerio) a potential alternative for the fish acute toxicity test? Comp. Biochem. Physiol. C Toxicol. Pharmacol. 149, 196-209. http://dx.doi.org/10.1016/j.cbpc.2008.11.006.

Langmead, B., Salzberg, S.L., 2012. Fast gapped-read alignment with Bowtie 2. Nat. Methods 9, 357-359. http://dx.doi.org/10.1038/nmeth.1923.

Lawson, N.D., Weinstein, B.M., 2002a. In vivo imaging of embryonic vascular development using transgenic zebrafish. Dev. Biol. 248, 307-318 S0012160602907116 [pii].

Lawson, N.D., Weinstein, B.M., 2002b. Arteries and veins: making a difference with zebrafish. Nat. Rev. Genet. 3, 674-682. http://dx.doi.org/10.1038/nrg888.

Lee, J.W., Won, E.J., Raisuddin, S., Lee, J.S., 2015. Significance of adverse outcome pathways in biomarker-based environmental risk assessment in aquatic organisms. J Env. Sci 35, 115-127. http://dx.doi.org/10.1016/j.jes.2015.05.002. S1001-0742(15) 00223-5 [pii].

Li, H., Handsaker, B., Wysoker, A., Fennell, T., Ruan, J., Homer, N., et al., 2009. The sequence alignment/map format and SAMtools. Bioinformatics 25, 2078-2079. http://dx.doi.org/10.1093/bioinformatics/btp352.

Manke, A., Wang, L., Rojanasakul, Y., 2013. Mechanisms of nanoparticle-induced oxidative stress and toxicity. Biomed. Res. Int. 942916. http://dx.doi.org/10.1155/ 2013/942916.

Meijer, A.H., Spaink, H.P., 2011. Host-pathogen interactions made transparent with the zebrafish model. Curr. Drug Targets 12, 1000-1017.

Moghimi, S.M., Andersen, A.J., Hashemi, S.H., Lettiero, B., Ahmadvand, D., Hunter, A.C., et al., 2010. Complement activation cascade triggered by PEG-PL engineered nanomedicines and carbon nanotubes: the challenges ahead. J Control. Release 146, 175-181. http://dx.doi.org/10.1016/j.jconrel.2010.04.003.

Pico, A.R., Kelder, T., van Iersel, M.P., Hanspers, K., Conklin, B.R., Evelo, C., 2008. WikiPathways: pathway editing for the people. PLoS Biol. 6, e184. http://dx.doi.org/ 10.1371/journal.pbio.0060184. 08-PLBI-CP-0724 [pii].

PlasticsEurope, 2015. Plastics - The Facts 2015.

Reimand, J., Kull, M., Peterson, H., Hansen, J., Vilo, J., 2007. g:Profiler-a web-based toolset for functional profiling of gene lists from large-scale experiments. Nucleic Acids Res. 35, W193-W200. http://dx.doi.org/10.1093/nar/gkm226. gkm226 [pii].

Reimand, J., Arak, T., Vilo, J., 2011. g:Profiler-a web server for functional interpretation of gene lists (2011 update). Nucleic Acids Res. 39, W307-W315. http://dx.doi.org/ 10.1093/nar/gkr378. gkr378 [pii].

Ricklin, D., Lambris, J.D., 2013. Complement in immune and inflammatry disorders: pathophysiological mechansism. J. Immunol. 190, 3831-3838. http://dx.doi.org/10. 4049/jimmunol.1203487.

Sarkar, A., Ghosh, M., Sil, P.C., 2014. Nanotoxicity: oxidative stress mediated toxicity of metal and metal oxide nanoparticles. J. Nanosci. Nanotechnol. 14, 730-743.

Schindelin, J., Arganda-Carreras, I., Frise, E., Kaynig, V., Longair, M., Pietzsch, T., et al., 2012. Fiji: an open-source platform for biological-image analysis. Nat. Methods 9 , 676-682. http://dx.doi.org/10.1038/nmeth.2019. nmeth.2019 [pii].

Scholz, S., Fischer, S., Gündel, U., Küster, E., Luckenbach, T., Voelker, D., 2008. The zebrafish embryo model in environmental risk assessment-applications beyond acute toxicity testing. Environ. Sci. Pollut. Res. Int. 15, 394-404. http://dx.doi.org/10. 1007/s11356-008-0018-z.

Skjolding, L.M., Ašmonaitė, G., Jølck, R.I., Andresen, T.L., Selck, H., Baun, A., et al., 2017. Assessment of the importance of exposure route for uptake and internal localization of fluorescent nanoparticles in zebrafish (Danio rerio) using light sheet microscopy. Nanotoxicology 11, 351-359. http://dx.doi.org/10.1080/17435390.2017.1306128.

Spaink, H.P., Cui, C., Wiweger, M.I., Jansen, H.J., Veneman, W.J., Marin-Juez, R., de Sonneville, J., et al., 2013. Robotic injection of zebrafish embryos for highthroughput screening in disease models. Methods 62, 246-254. http://dx.doi.org/10. 1016/j.ymeth.2013.06.002.

Stegeman, J.J., Goldstone V, J., Hahn, M.E., 2010. Perspectives on zebrafish as a model in environmental toxicology. Fish Physiol. 29, 367-439. http://dx.doi.org/10.1016/ s1546-5098(10)02910-9.

Strähle, U., Bally-Cuif, L., Kelsh, R., Beis, D., Mione, M., Panula, P., et al., 2012 EuFishBioMed (COST Action BM0804): a European network to promote the use of small fishes in biomedical research. Zebrafish 9, 90-93. http://dx.doi.org/10.1089/ zeb.2012.0742.

Surai, P.F., Speake, B.K., Decrock, F., Groscolas, R., 2014. Transfer of Vitamins E and A from yolk to embryo during development of the king penguin (Aptenodytes 
patagonicus). Physiol. Biochem. Zool. 74, 928-936. http://dx.doi.org/10.1086/ 338062.

Van Pomeren, M., Brun, N.R., Peijnenburg, W.J.G.M., Vijver, M.G., 2017. Exploring uptake and biodistribution of polystyrene (nano) particles in zebrafish embryos at different developmental stages. Aquat. Toxicol. 190, 40-45. http://dx.doi.org/10.1016/ j.aquatox.2017.06.017.

Veneman, W.J., Stockhammer, O.W., de Boer, L., Zaat, S.a., Meijer, A.H., Spaink, H.P. 2013. A zebrafish high throughput screening system used for Staphylococcus epidermidis infection marker discovery. BMC Genomics 14, 255. http://dx.doi.org/10 1186/1471-2164-14-255.

Veneman, W.J., de Sonneville, J., van der Kolk, K.J., Ordas, A., Al-Ars, Z., Meijer, A.H., et al., 2014. Analysis of RNAseq datasets from a comparative infectious disease zebrafish model using GeneTiles bioinformatics. Immunogenetics 67, 135-147. http://dx.doi.org/10.1007/s00251-014-0820-3.

Whyte, S.K., 2007. The innate immune response of finfish - a review of current knowledge. Fish Shellfish Immunol. 23, 1127-1151. http://dx.doi.org/10.1016/j.fsi.2007. 06.005 .

Wink, S., Hiemstra, S., Huppelschoten, S., Danen, E., Niemeijer, M., Hendriks, G., et al., 2014. Quantitative high content imaging of cellular adaptive stress response pathways in toxicity for chemical safety assessment. Chem. Res. Toxicol. 27, 338-355. http://dx.doi.org/10.1021/tx4004038.

Zhang, S., Cui, P., 2014. Complement system in zebrafish. Dev. Comp. Immunol. 46, $3-10$.

Zolnik, B.S., González-Fernández, Á:, Sadrieh, N., Dobrovolskaia, M.A., 2010. Minireview: nanoparticles and the immune system. Endocrinology 151, 458-465. http://dx.doi.org/10.1210/en.2009-1082. 